\title{
Treatment of Wastewater from Purified Terephtalic Acid (PTA) Production in a Two-stage Anaerobic Expanded Granular Sludge Bed System
}

\author{
Young-Shin Lee ${ }^{1}$, Gee-Bong $\operatorname{Han}^{2 \dagger}$ \\ ${ }^{1}$ Department of Environment Engineering, Hanseo University, Seosan 356-706, Korea \\ ${ }^{2}$ Department of Biosciences \& Environmental Engineering, The Catholic University of Korea, Bucheon 420-743, Korea
}

\begin{abstract}
The wastewater treatment with a two-phase expanded granular sludge bed (EGSB) system for anaerobic degradation of acetate, benzoate, terephtalate and $p$-toluate from purified terephtalic acid (PTA) production was studied. The feasibility and effectiveness of the system was evaluated in terms of organic oxidation by chemical oxygen demand (COD), gas production, bacterial adaptability and stability in the granular sludge. Average removal efficiencies $93.5 \%$ and $72.7 \%$ were achieved in the EGSB reactors under volumetric loading rates of $1.0-15 \mathrm{~kg}-\mathrm{COD} / \mathrm{m}^{3} / \mathrm{day}$ and terephtalate and $p$-toluate of $351-526 \mathrm{mg} / \mathrm{L}$, respectively. Gas production reached total methane production rate of $0.30 \mathrm{~L} / \mathrm{g}$-COD under these conditions in the sequential EGSB reactor system. Higher strength influent COD concentration above $4.8 \mathrm{~g}-\mathrm{COD} / \mathrm{L}$ related to field conditions was fed to observe the disturbance of the EGSB reactors.
\end{abstract}

Keywords: Anaerobic treatment, Expanded granular sludge bed (EGSB), Purified terephtalic acid (PTA), Two-phase, Wastewater

\section{Introduction}

PTA (1,4-benzenedicarboxylic acid, $\mathrm{C}_{6} \mathrm{H}_{4}(\mathrm{COOH})_{2}$ ) is purified via hydrogenation of crude terephthalic acid and widely used as the main raw colorless solid material in the manufacturing of various petrochemical products [1,2]. A high strength organic PTA wastewater is generated from the major sources of wastewater generation such as the oxidation and purification processes during the PTA manufacturing procedures. The PTA scrubbing section generates the maximum quantity of wastewater corresponding to 5-20 kg-COD $/ \mathrm{m}^{3}$ with $3-10 \mathrm{~m}^{3}$ wastewater/t PTA production [3, 4]. Accordingly, terephthalate, acetate, benzoate, and $p$-toluate are the major organic contaminants, but trimellitic acid, o-phthalic acid and 4-carboxybenzaldehyde are also contaminants found to be removed in the wastewater [5, 6].

Anaerobic processwas developed to treat more complicated and higher strength organic wastewater such as aromatic compounds in the PTA wastewaters [7, 8]. Considering the constituents in PTA wastewater, acetate and benzoate are readily degradable, but on the contrary terephthalate and $p$-toluate are hardly degradable. Further, the concentration of benzoate and acetate in the PTA wastewater affect the biological degradation of terephthalate and $p$-toluate during the treatment. The poor degradability of $p$-toluate at very low rates in anaerobic reactions was also another reason $[9,10]$. Kleerebezem et al. $[11,12]$ reported that the slow biodegradation of terephthalate caused the complex inhibition effects of acetate and benzoate on the inefficient degradation of terephthalate under artificial PTA-wastewater treatment. Kleerebezem et al. [13] also reported that degradation of terephthalate limitedthe rate of anaerobic treatment of PTA-wastewater in lab-scale UASB-reactors.

Because of the low $5 \%-20 \%$ of the volumetric loading rate by $p$-toluate, $p$-toluate was less relevant to high volumetric loading rate and removal efficiency during anaerobic pre-treatment. Thus major problems in the anaerobic treatment of PTA production wastewater were chemical inhibition effects and shock loads [14, 15]. However, benzoate, terephthalate, and p-toluate concentrations in PTA production wastewater were not harmful to acetoclastic and hydrogenotrophic methanogens at the levels contained in PTA production wastewater [16].

Kleerebezem and Lettinga [1] suggested a consecutive anaerobic system in order to prohibit inhibition of terephthalate degradation by acetate and/or benzoate under the operational circumstances by spatial separation of acetate and benzoate degradation in the c) (1) \$ This is an Open Access article distributed under the terms of the Creative Commons Attribution Non-Commercial License (http://creativecommons. org/ licenses/by-nc/3.0/) which permits unrestricted non-commercial use, distribution, and reproduction in any medium, provided the original work is properly cited.
Received September 3, 2104 Accepted November 24, 2014

$\dagger$ Corresponding author

E-mail: geebhan@catholic.ac.kr

Tel: +82-2-2164-4878 Fax: +82-2-2164-4765

Copyright (C) 2014 Korean Society of Environmental Engineers 
earlier stage and degradation of terephthalate (and $p$-toluate) in the post stage [17]. Up-flow anaerobic sludge blanket (UASB) and expanded granular sludge bed (EGSB) systems are aggregating cluster of microorganisms in dense granular sludge bed. EGSB system is a modification of the traditional UASB system to obtain the better hydrodynamic function, so EGSB improved the Feeding and the contact between the wastewater and the sludge bed in the system [18, 19]. To overcome chemical inhibition and shock loads for the treatment of PTA-production wastewater, expanded-bed granular activated carbon anaerobic reactor was applied [20]. However the high-rate anaerobic bioreactor system has not yet fully developed for the complex process dynamics and some important metabolisms of the involved microorganisms and thus operation of a full-scale system is still in a challenging stage [9].

In this study, anaerobic treatment of a real PTA production wastewater with a two-stage EGSB system was tested for chemical inhibition of acetate, benzoate, $p$-toluate, and terephthalate. Shock loadings including the use of various Feed ratios of low and high level concentrations of PTA production wastewater were tested. The results obtained with the high-rate two-stage EGSB reactor system is discussed whether the most practical applicability for high-rate anaerobic spatial treatment of PTA production wastewater.

\section{Materials and methods}

\subsection{EGSB Reactors System}

A process diagram of the two-stage anaerobic EGSB system is shown in Fig. 1. Two 6 L identical EGSB reactors (I-EGSB and II-EGSB) with a diameter of $80 \mathrm{~mm}$ and height of $1.2 \mathrm{~m}$ were made of polyacrylate resin.

To expand the granular sludge biomass, the wastewater in the EGSB reactor was circulated from the top to the bottom and the working volume of $5.0 \mathrm{~L}$ resulted in both EGSB reactors. The water temperature in both I-EGSB and II-EGSB reactor was maintained at $34-36 \pm 1^{\circ} \mathrm{C}$ using electric heating coils. The biogas from

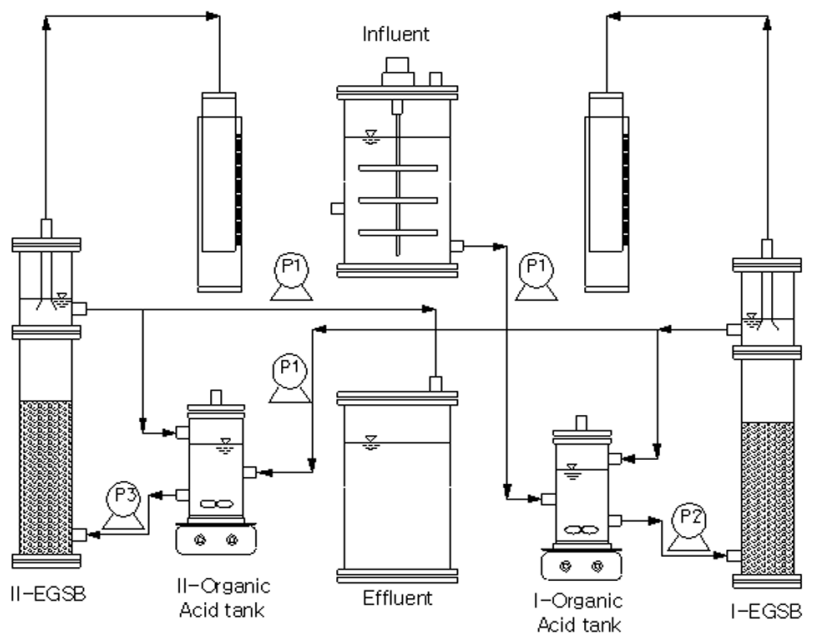

Fig. 1. Process diagram of the two-stage expanded granular sludge bed (EGSB) reactors system. both reactors was collected from the top of the reactors by the gas-holders. The influent and recirculation flow were feeded in a Feeding organic acid tank (T-I) prior to introduction into I-EGSB. The influent was buffered to be $\mathrm{pH} 6.7$ with $\mathrm{NaHCO}_{3}$ and fortified with nutrients $\left(\mathrm{NH}_{4} \mathrm{Cl}\right.$ and $\left.\mathrm{KH}_{2} \mathrm{PO}_{4}, 5: 1\right)$. Nutrient $\mathrm{COD}$ ratios were maintained at 200:5:1 (COD : N : P). The I-EGSB effluent was collected in an external Feeding organic acid tank (T-II) prior to introduction into the second stage (II-EGSB). The first stage reactor (I-EGSB) was used for the stabilization of a volatile fatty acid (VFA)-based PTA production wastewater consisting of acetate and benzoate to a total of $4.9 \mathrm{~g}-\mathrm{COD} / \mathrm{L}$. The second stage reactor (II-EGSB) of the two-stage anaerobic system was adjusted to maintain the terephthalate degrading granular sludge. The system was operated at various volumetric loading rates (VLRs) to obtain the optimized performance of the EGSB system.

\subsection{Start-up and Operation of the EGSB System}

The I-EGSB and II-EGSB were each inoculated with granular sludge from an anaerobic digester of sewage treatment plant to provide granular sludge as a carrier material for the terephthalate and $p$-toluate degrading suspended culture capable of degrading the constituents in the PTA production wastewater.

Both reactors were inoculated with $20 \mathrm{~g}$ VSS/L biomass (volatile suspended solids) and further stabilized with $30 \mathrm{~g}$ VSS/L biomass at the full development of the granular sludge bed. The sludge was continuously fed for 10 day using $10 \mathrm{~g}$ /day of sucrose, 250 $\mathrm{mg} /$ day of nitrogen as $\mathrm{NH}_{4} \mathrm{Cl}$, and $50 \mathrm{mg}$ /day of phosphorus as $\mathrm{K}_{2} \mathrm{HPO}_{4}$. The sludge for EGSB-II was acclimatized by gradual introduction of the PTA wastewater discharged from a PTA manufacturing plant (KP Chemical, Ulsan, Korea).

In the first phase, to induce granular sludge bed development on the reactors with the recirculation pump of which flow rate was maintained at 1.5-15 L/hr, the I-EGSB and II-EGSB were operated in a batch mode. After one month from the initial phase start-up, the operation was switched to a continuous mode (operation 1). In the first phase, feeding flow rate was $0.35 \mathrm{~L} /$ day which is corresponding to the hydraulic retention time (HRT) of 14.3 day. Then, the feeding flow rate was gradually increased up to $20 \mathrm{~L} /$ day (HRT $=6.0 \mathrm{hr}$ ) for 300 days operation. The superficial velocity of I-EGSB and II-EGSB applied through the recirculation with T-I and T-II was increased from 0.52 to $2.9 \mathrm{~m} / \mathrm{hr}$. In time the VLR of the reactor was gradually increased up to $15 \mathrm{~kg}-\mathrm{COD} / \mathrm{m}^{3} /$ day for 10 months with increasing the influent flow rate. The first operational conditions in the two-stage EGSB system are listed in Table 1.

The system was fed to evaluate the shock load impacts on the system from fluctuations of the influent concentration with 3 different PTA production wastewater containing a Feedture of high and low level concentrations in the ratios of 1:74 (Feed 1), 2:73 (Feed 2) and 3:72 (Feed 3) comparable to those possibly found in PTA production wastewater (the 2nd operation). The second operational conditions in the two-stage EGSB system are listed in Table 2. Initial feeding flow rate of $18 \mathrm{~L} /$ day corresponding to the HRT of $6.7 \mathrm{hr}$ was gradually increased up to $20 \mathrm{~L} /$ day $(\mathrm{HRT}=6.0 \mathrm{hr})$ for 40 day operation of each Feed. The anaerobic EGSB reactors were further operated over 4 months for the fluctuation test of the EGSB under shock load conditions. 
Table 1. Physico-chemical Characteristics of Operation 1 in the Two-staged expanded granular sludge bed (EGSB) System

\begin{tabular}{lccc}
\hline \multirow{2}{*}{ Parameters } & \multirow{2}{*}{ Influent } & \multicolumn{2}{c}{ Effluent } \\
\cline { 3 - 4 } & & EGSB-I & EGSB-II \\
\hline Operating time (day) & 300 & 300 & 300 \\
Flow rate (L/day) & $0.30-16$ & $0.30-16$ & $0.30-16$ \\
Superficial velocity (m/hr) & & $0.52-2.9$ & $0.52-2.9$ \\
Terephthalate (mg/L) & $48-503$ & $46-253$ & $25-68$ \\
p-toluate (mg/L) & $40-466$ & $35-430$ & $23-64$ \\
Acetate (mg/L) & $106-1,708$ & $90-115$ & $10-41$ \\
Benzoate (mg/L) & $105-730$ & $45-92$ & $9-18$ \\
COD (mg/L) & $468-4,855$ & $293-1,502$ & $107-216$ \\
VLR (kg-COD/m $/$ day) & $1.9-15$ & $1.3-6.8$ & $0.4-1.2$ \\
\hline
\end{tabular}

COD: chemical oxygen demand, VLR: Volumetric loading rates.

Table 2. Operating Conditions in the Two-stage expanded granular sludge bed (EGSB) System

\begin{tabular}{lccc}
\hline \multicolumn{1}{c}{ Parameters } & Feed1 (1:74) & Feed2 (2:73) & Feed3 (3:72) \\
\hline Operating time (day) & 100 & 100 & 100 \\
Flow rate (L/day) & 18 & 18 & 18 \\
Terephthalate (mg/L) & $448-503$ & $536-578$ & $624-678$ \\
p-toluate (mg/L) & $424-435$ & $455-467$ & $533-541$ \\
Acetate (mg/L) & $823-852$ & $727-748$ & $642-653$ \\
Benzoate (mg/ L) & $679-659$ & $579-591$ & $481-497$ \\
COD (mg/L) & $3,904-3,926$ & $3,927-3,951$ & $3,953-3,972$ \\
VLR (kg-COD/m³/day) & 15 & 15 & 15 \\
\hline
\end{tabular}

COD: chemical oxygen demand, VLR: Volumetric loading rates.

\subsection{Analytical Methods}

A HPLC (Ultimate 3000; DIONEX, USA) equipped with UV/Vis-detector (VWD3400; DIONEX, USA) was used to analyze all organic contaminants (except acetate) in the PTA wastewater. The Agilent C18 (250 mm $\times 4.5 \mathrm{~mm}$ ) separation column with packing size of $5 \mu \mathrm{m}$ and the detection wavelength of $230 \mathrm{~nm}$ was used. A carrier liquid at the flow rate of $1 \mathrm{~mL} / \mathrm{min}$ with a Feedture of methanol-acetic acid (4:6 v/v) was used. A Hewlett Packard gas chromatograph (model HP 6890) equipped with a flame ionization detector and a capillary column (HP-INNOWAX, $30 \mathrm{~m} \times 0.32 \mathrm{~mm}$ i.d.) was used to determine acetic acid. The temperature profile was controlled initially $60^{\circ} \mathrm{C}$ for $5 \mathrm{~min}$, and then adjusted to $300^{\circ} \mathrm{C}$ at the rate of $5^{\circ} \mathrm{C} / \mathrm{min}$. A carrier gas consisting of nitrogen saturated with formic acid was used at the flow rate of $2 \mathrm{~mL} / \mathrm{min}$. For the analysis of TSS and VSS in sludge samples, and COD measurements followed the directions in Standard Methods [21]. The biogas production was monitored each day by collecting the volume and composition data of the biogas collected in the gasholder. A HACH model DR4000 was used to measure alkalinity. The liquid sample $\mathrm{pH}$ was measured by using an ORION model 3STAR (Orion, USA) pH meter.

\section{Results}

\subsection{Efficiency of a Sequential Two-stage EGSB System}

The removal of acetate and benzoate in the first stage can enhance terephthalate and $p$-toluate degradation in the second stage because strongly fluctuating acetate and benzoate loading rates primarily can affect the biodegradation of terephthalate and $p$-toluate. Acetate and benzoate in the PTA production wastewater are easily biodegradable organic constituents but biodegradability of terephthalate and $p$-toluate is unclear. As a consequence, anaerobic degradation of terephthalate and $p$-toluate in the second stage is preferred $[13,17]$. Curves of influent VLR and COD concentration in the two-stage anaerobic EGSB system is designated in Fig. 2.

Until 50 days of feeding from start up in the first phase of operation as shown in Fig. 2, influent COD of some acetate and benzoate was incompletely degraded in I-EGSB and was introduced into II-EGSB during this period. This resulted in the relatively high effluent COD concentration of terephtalate and $p$-toluate in II-EGSB (Fig. 2(b)). After 50 days, the VLR was gradually increased step by step up to $15.0 \mathrm{~kg}-\mathrm{COD} / \mathrm{m}^{3} /$ day and this condition was maintained for up to 250 days. In the first phase of operation, the feeding period from 50 to 140 days, it seemed that most organic constituents except terephtalate and $p$-toluate were almost degraded in I-EGSB although some unexpected disturbances were observed due to VLR increase.

The total COD concentration of PTA production wastewater was average $7.2 \mathrm{~g} \mathrm{COD/L}$, and VLR with acetate and benzoate corresponding to $75 \%-85 \%$ of the total was reduced in the first stage of the two-stage reactor system at very high rates $(<15$ $\mathrm{kg}-\mathrm{COD} / \mathrm{m}^{3} /$ day), while VLR with terephthalate and $p$-toluate was reduced in the 2nd stage at moderate rates (average 1.5 $\mathrm{kg}-\mathrm{COD} / \mathrm{m}^{3} /$ day) as shown in Fig. 2(a) and 2(b), respectively.
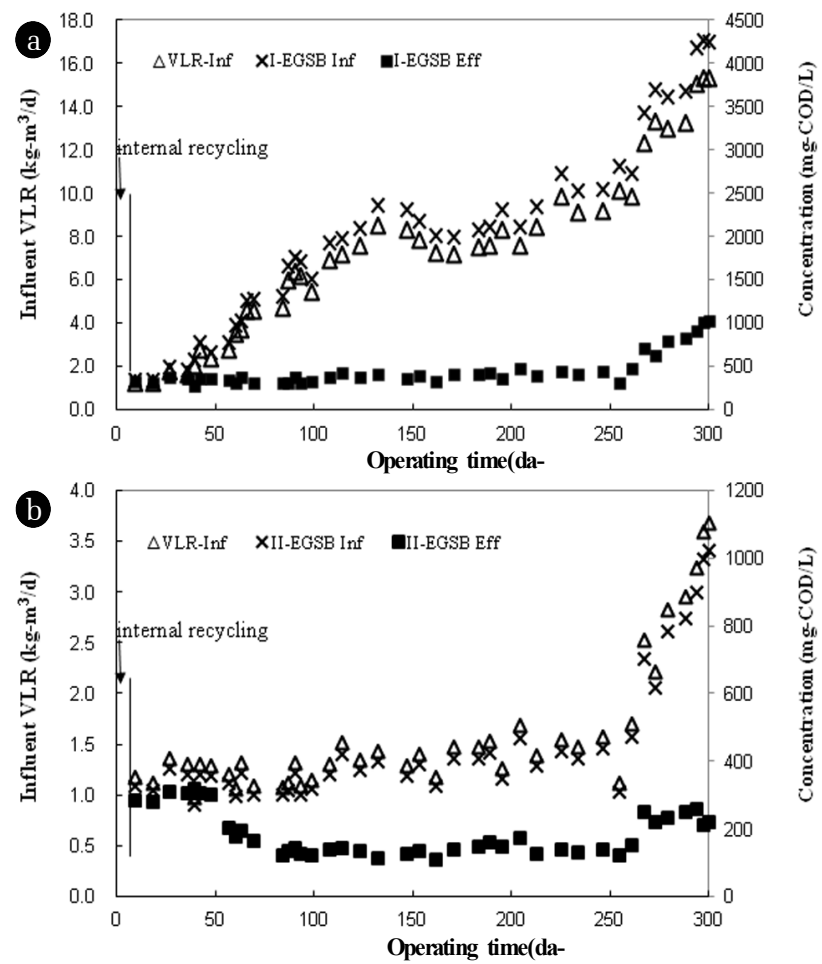

Fig. 2. Curves of influent VLR and COD concentration in the two-stage anaerobic EGSB system. 
The optimized COD reduction efficiency of 93.5\% resulted at $6 \mathrm{hr}$ of HRT with high concentrations of granular sludge biomass (up to $30 \mathrm{~g}$ VSS/L) when the two-stage EGSB system was operated under maximum VLR of $15 \mathrm{~kg}-\mathrm{COD} / \mathrm{m}^{3} /$ day. Thus the optimized COD reduction efficiencies were obtained to be considerably higher than those in a previous study with UASB reactors [12].

\subsection{Biogas Production}

The emissions of biogas were observed during 270 days of operation under a direct relationship with the volatile solids content. Biogas production was not obtained within 10 days during start-up from the I-EGSB reactor, although some COD was reduced. Thus the acclamation time to degrade organic constituents in the influent seems to be required in the first stage biogas production under newly imposed conditions. After gas production started at day 11 , more steady daily gas volumes started to be obtained. If a steady-state condition is satisfied the methane production rate should be strongly correlated with the COD removal rate. The methane production from the two-stage EGSB during the continuous operation is shown in Fig. 3.

After 30 days of continuous operation of the two-stage EGSB process, methane biogas started to be produced gradually and increased rapidly. The steady-state methane production rates were obtained about 0.27 and $0.04 \mathrm{~L} / \mathrm{g}-\mathrm{COD}$ from I-EGSB and II-EGSB, respectively. The total methane production rate at the pseudo-steady-state condition from the EGSB reactors reached to the maximum of $0.30 \mathrm{~L} / \mathrm{g}-\mathrm{COD}$ after about 135 days operation although some observed fluctuations. The methane yield obtained with the EGSB reactor is close to the stoichiometric value (0.35 L/g-COD); this means that the most COD reduced was actually converted to methane, and much less accumulation of influent organic constituents occurred.

After 120 days operation of the EGSB process, the methane biogas yields from I-EGSB and II-EGSB were stabilized to be enough for the true steady-state conditions finally achieved for the optimized operating conditions. The stabilized methane biogas yields in I-EGSB and II-EGSB were calculated to be about 0.27 and 0.04 L/g-COD, respectively, both of which were rather lower than the theoretical methane yield value of $0.35 \mathrm{~L} / \mathrm{g}$-COD. The maximum methane biogas production rates achieved in each stage of EGSB process were 0.30 and $0.04 \mathrm{~L} / \mathrm{g}$-COD, respectively.

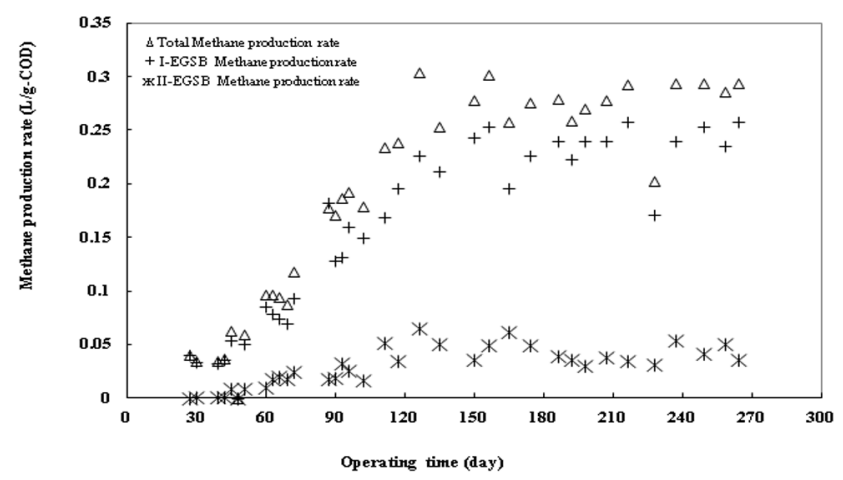

Fig. 3. The profile of methane production from expanded granular sludge bed (EGSB).

\subsection{Microbial Feature in the Sludge Granules}

A SEM model HITACH S-4800 with an ion sputter model E-1045 (15A, $60 \mathrm{sec}$ ) was used to image the morphological characteristics of granules for analysis of the microbial distribution within granular sludge in EGSB reactors. Fig. 4(a) and 4(b) showed the different surface and inside images of the granules of I-EGSB and II-EGSB.

From the SEM images of the granules, where it can be recognized that more densed biofilm with smooth surface was noticed at the I-EGSB granule while a rather coarse surface at the II-EGSB granule compared to the I-EGSB granule was imaged. Baloch et al.[22] reported that methanogens are usually acclimated in the favorable conditions observed for the I-EGSB granule and acidogens are favorable of the II-EGSB granules.

However, the superficial organic compounds biodegradation characteristics of the I-EGSB and II-EGSB granules were quite similar to each other. Therefore their organic compounds biodegradation rates could be clearly discriminated in that biodegradation rate for acetate and benzoate with the I-EGSB granule was faster than that of the II-EGSB granule whereas vice versa for biodegradation rate of terepthalate and $p$-toluate. Though the granular biomass concentrations in both reactors during start-up period were almost same, it could be noticed that degradation rates might be different due to the spatial distributions of microorganisms within the granules, which could be varied depending on the concentrations of the influent organic compounds.
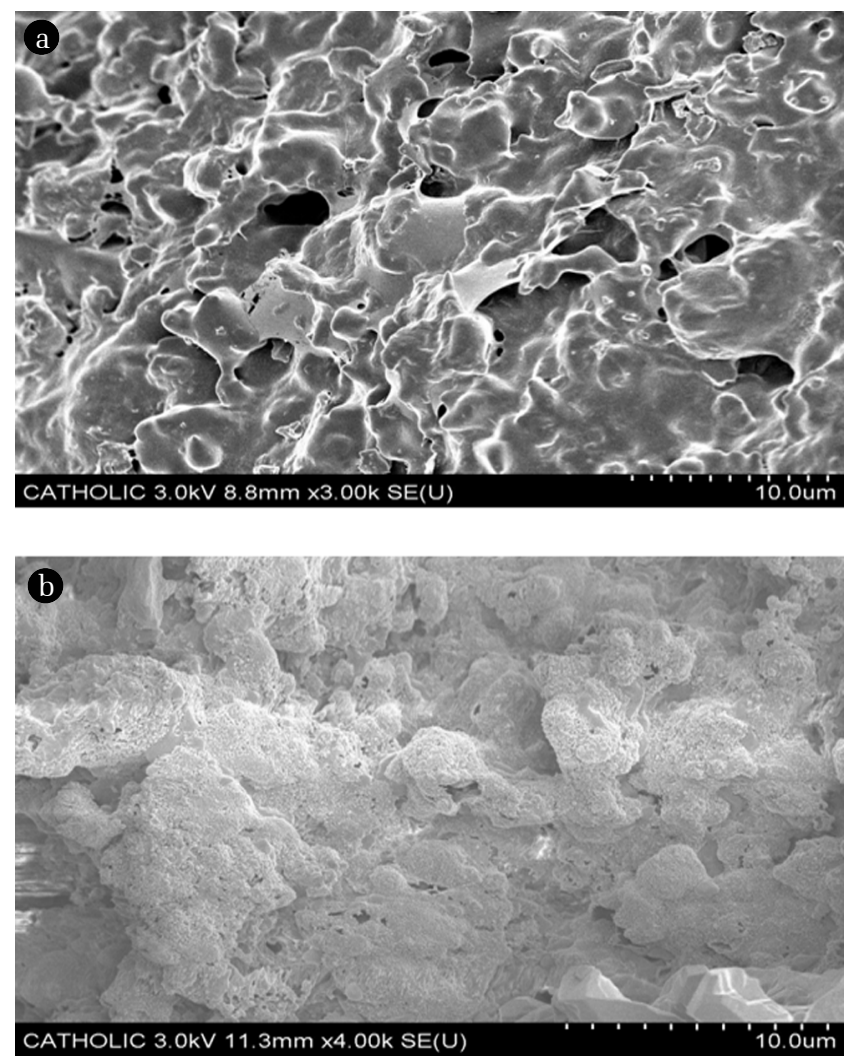

Fig. 4. Scanning electron micrographs of granule in EGSB reactors: (a) I-EGSB surface and inside, (b) II-EGSB surface and inside. 


\subsection{Fluctuation Test with Higher Constituents in Influent}

The responses of the system to shock loads of influent are designated in Fig. 5 with the COD reduction efficiency and effluent concentrations of terephthalate and $p$-toluate in the PTA wastewater during the fluctuation test. Fluctuation test with highly concentrated raw waste was conducted for the responses of the system to shock loads with PTA wastewater containing a mixture of higher constituents in the ratios of 1:74 (Feed 1), 2:73 (Feed 2) and 3:72 (Feed 3), which is comparable to the concentrations possibly found in PTA production wastewater as shown in Table 2.

During 300 day of operation the influent of a mixture of high and low level concentrations was supplied with the ratio of 2:73 for Feed 2 and 3:72 for Feed 3 to test whether the increased concentration of organic constituents in influent would disturbance the efficiency of PTA production wastewater treatment. During these tests the maximum volumetric loading rate was increased to 7.5 $\mathrm{kg}-\mathrm{COD} / \mathrm{m}^{3} /$ day, the VLR reduction efficiency reached a stable
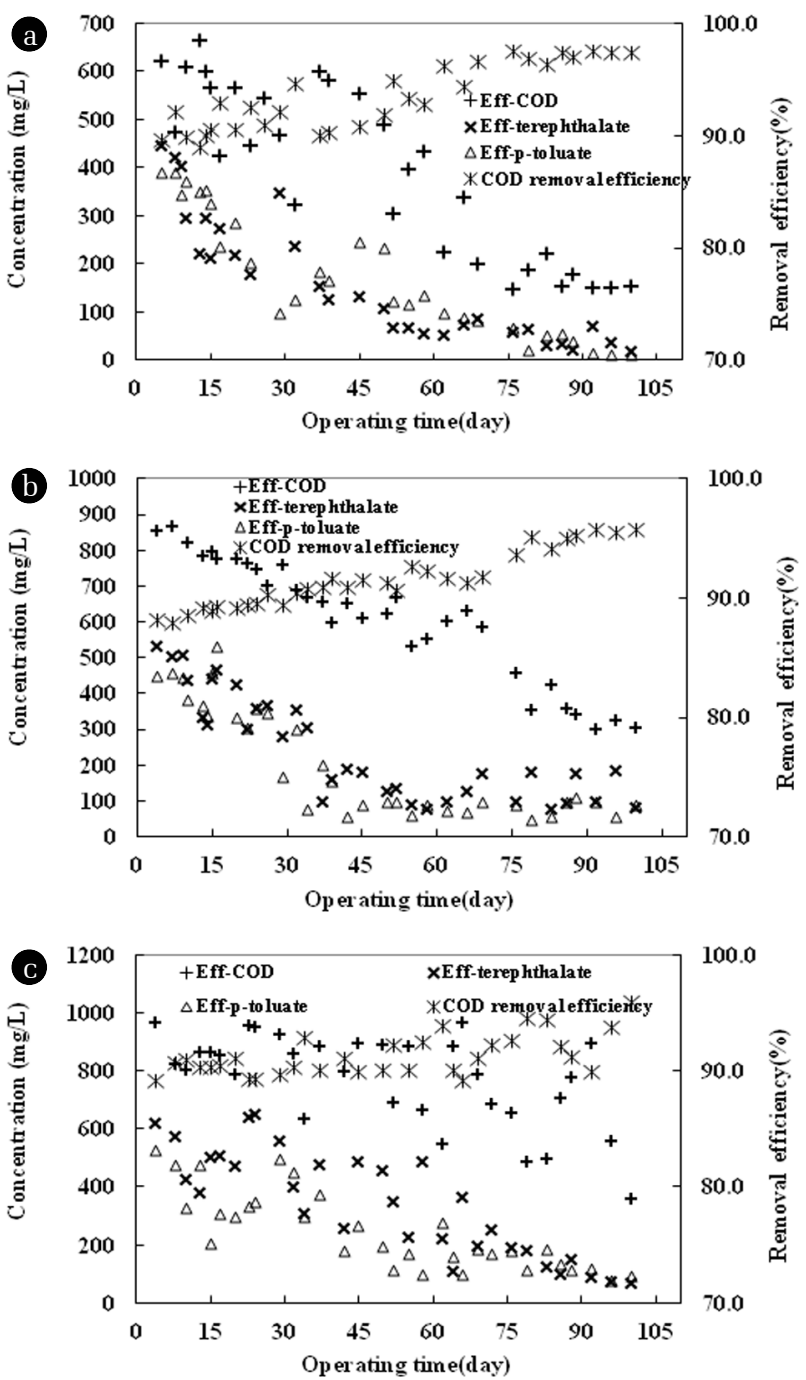

Fig. 5. The responses to the influent disturbance of the two-stage EGSB system during fluctuation test (a) for Feed 1 (b) for Feed 2 (c) for Feed 3. value of approximately $12.9 \mathrm{~kg}-\mathrm{COD} / \mathrm{m}^{3} /$ day. During 100 days for Feed 1 the influent of a mixture with high and low level concentrations in the ratio of 1:74 was supplied to the system. The COD removal capacity and effluent concentrations of terephtalate and $p$-toluate under the condition of Feed 1 are shown in Fig. 5(a). The condition of Feed 1 contributes to the system resulting in increasing $11 \%-15 \%$ of influent terephtalate and $p$-toluate concentrations in I-EGSB. Even with the fluctuation in the influent concentration, COD accumulated in the effluent to the maximum range of only 108-293 mg-COD/L, and the COD reduction efficiency was maintained as high as $93.2 \%$ and average $90.5 \%$. Terephthalate concentration of $448-503 \mathrm{mg} / \mathrm{L}$ in I-EGSB had decreased to less than $6 \mathrm{mg} / \mathrm{L}$ in the effluent of II-EGSB. Terephthalate and $p$-toluate inhibited no microbial groups associated with the earlier stage of benzoate and acetate degradation in I-EGSB. The influent shock loads did not affect the degradation of either acetate or benzoate but COD removal efficiency was decreased in the system.

For Feed 2 test a mixture of high and low level concentrations in the ratio of 2:73 was fed to I-EGSB. Due to the increased COD loading rate, the COD reduction was affected to be poor. The COD reduction efficiencies of average $89.6 \%$ were obtained under the VLR of $15 \mathrm{~kg}-\mathrm{COD} / \mathrm{m}^{3} /$ day during Feed 2 test. The observed results of Feed 2 test are shown in Fig. 5(b). Before terephthalate concentrations in the influent were increased to $436-578 \mathrm{mg} / \mathrm{L}$, degradation of benzoate and acetate were maintained stably and initially terephthalate degradation in I-EGSB was not obtained. However terephthalate concentration of less than $11 \mathrm{mg} / \mathrm{L}$ in the effluent was maintained in II-EGSB throughout Feed 2 test. The influent fluctuation with shock-loads resulted in minor decrease in the COD removal capacity to $12.7 \mathrm{~kg}-\mathrm{COD} / \mathrm{m}^{3} / \mathrm{day}$.

During Feed 3 test the terephthalate concentration in the effluent of I-EGSB was sustained to be similar as that in the influent at the start up. Thus the treatment efficiency was worsened after a further increase in the COD and terephthalate concentrations of 3,963 and $678 \mathrm{mg} / \mathrm{L}$ in the influent for Feed 3 test, respectively. The effect of fluctuations by the increased mixture ratio of the influent for Feed 3 test was shown in Fig. 5(c). The average COD removal efficiency of $86.8 \%$ observed from Feed 3 test was lower than that of Feed 2 test and even much lower to that of Feed 1 test. As can be seen in Fig. 5(c), terephthalate concentration in the effluent was not declined as much as the previous tests after the deterioration of Feed 3 test. During Feed 3 test the influent was fed steadily to the system with COD loading rate of $15 \mathrm{~kg}-\mathrm{COD} / \mathrm{m}^{3} /$ day, while removal efficiency was declined further to COD reduction capacity of $11.9 \mathrm{~kg}-\mathrm{COD} / \mathrm{m}^{3} / \mathrm{day}$. The lowest COD removal efficiencies for Feed 3 test may be caused by the fact that the influent concentration of terephtalate and $p$-toluate was average about $19.5 \%$ higher than that of Feed 1 test. The COD removal efficiencies obtained during 3 Feed tests revealed that the overall reduction efficiencies worsened to some extent after introducing the highly concentrated PTA production wastewater. This result seems to be related to the extent of effluent concentration of terephthalate from I-EGSB of which trend is different from those around the Feed 1 and Feed 2 fluctuations. 


\section{Discussion}

There is a better hydraulic distribution of the effluent in EGSB system because the granular sludge in the EGSB reactor is distributed in its entire volume, while in a UASB reactor the sludge is located at the bottom, forming a sludge blanket. Thus the EGSB reactor was much better than the UASB reactor in treating PTA production wastewater at the optimized rates of VLR (average $7.2 \mathrm{~kg}-\mathrm{COD} / \mathrm{m}^{3} /$ day) with superficial velocity of $3 \mathrm{~m} / \mathrm{hr}$ and a better Feeding of the granular sludge owing to an increase in the biogas production, which would improve substrate transfer.

If higher granular biomass concentration is obtainable, high rate degradation of acetate and benzoate in anaerobic system can be achieved within 1 month, but start-up of a UASB reactor using suspended methanogenic biomass may take much longer [11]. Due to the higher gas production rates per unit of reactor surface, a full scale UASB reactor may not be feasible to retain the high biomass concentrations (> 45 g VSS/L). However, EGSB reactors show steady granular sludge particulate expansion by high superficial velocities (2-15 m/hr), resulting in the better gas liquid separation capacity [3]. Fajrado et al.[16] reported that terephthalic acid and aromatic compounds (dimethylterphthalate) resulted no inhibition effects to anaerobic treatment of easily biodegradable compounds (acetic, benzoic and formic acids) remaining in PTA wastewater during $40 \%-50 \%$ COD removal by anaerobic digestion system.

The microbial population of involved granule culture was so fluctuate to the changes of the operating conditions, therefore more sufficient time should have been provided in order to achieve a true steady-state for soluble pollutant dynamics. The hydraulic characteristics of the EGSB reactor favored degradation of acetate and benzoate in the influent and conversion of soluble organic constituents to methane, reducing wastewater potential toxicity. Due to the affection of actual concentrations of acetate and benzoate in I-EGSB to the terephthalate and $p$-toluate removal capacity, the elevated acetate and benzoate loading rates in the first phase must have inhibited degradation of terephthalate and $p$-toluate in I-EGSB.

In the two-phase system, the removal of the organic constituents in the first phase would first result in the depletion of the readily biodegradable compounds like acetate and benzoate, as long as the acetate and benzoate levels are controlled in the first phse less than the treatment capacity of the second phase. This condition would provide a more favorable environment for the terephthalate and $p$-toluate degrading microorganisms in the second phase. Once these microorganisms are more activated in the second phase due to the favored environment, the syntrophic bacteria would maintain an enhanced treatment capacity even though the organic loading rate is increased.

The acetate and benzoate degradation rate in I-EGSB was increased highly enough to sustain the terephtalate and $p$-toluate degradation rate over $80 \%$ in II-EGSB. Under the two-phase EGSB system, the acclimation process in II-EGSB enhanced the seeded biomass originally containing some microorganisms and their degrading capability of terephtalate and $p$-toluate. Accordingly, it seems that the two-single phase process would be favorable for the PTA wastewater treatment in the case that even operating VLR is increased.

Joung et al. [9] showed that the anaerobic degradation of terephtalate and $p$-toluate seems to be adversely affected by the presence of acetate and benzoate. The main advantage of the two-phase anaerobic reactor system was reduction of the lag-phase prior to terephthalate and $p$-toluate degradation in the second phase. Benzoate is also known to inhibit the terephtalate degradation [16]. Furthermore, high conversion rate was also achieved by the high concentrations of granular sludge biomass (up to $30 \mathrm{~g} \mathrm{VSS} / \mathrm{L}$ ) sustained in EGSB reactors. Thus the volumetric COD reduction abilities are considerably higher and this study evidently shows that high-rate treatment of a mixture of acetate, benzoate, $p$-toluate and terephthalate is feasible with the two-phase EGSB system.

The EGSB system may therefore be the most suitable for practical implementation of high-rate anaerobic treatment of PTA production wastewater. The results showed in this study evidently suggest that high rate pre-reduction of acetate and benzoate in the two-phase anaerobic EGSB system is a feasible application for PTA-wastewater. As a consequence, the two-phase anaerobic EGSB system for this study was affordable to adopt with sequential two EGSB-bioreactors in series.

\section{Conclusions}

The following conclusions can be inferred based on this study:

- Due to high concentrations of granular sludge biomass (up to $30 \mathrm{~g} \mathrm{VS} / \mathrm{L})$, much higher volumetric reduction rate $(93.5 \%$ of $15 \mathrm{~kg}-\mathrm{COD} / \mathrm{m}^{3} /$ day) was obtained, resulting high rate degradation of acetate and benzoate in the first phase with a comparatively smaller reactor volumes. Therefore EGSB reactor system may be feasible for successful practical implementation of high-rate anaerobic pre-treatment of PTA production wastewater.

- Due to pre-removal of acetate and benzoate in the first stage, terephthalate degrading capacity in the second stage can be enhanced at prolonged SRT-values. Thus main advantage of the two-phase anaerobic EGSB system is spatial separation for reduction of acetate and benzoate prior to terephthalate and $p$-toluate degradation in the second phase.

- The fluctuating acetate and benzoate loading rates primarily affect the terephthalate and $p$-toluate removal capacity and concentrations of acetate and benzoate of the effluent in the second phase can also be minimized. Accordingly, anaerobic degradation of terephthalate and $p$-toluate in the second phase remains to be preferred.

- Influent flow with sustaining up-flow superficial velocity of $2 \mathrm{~m} / \mathrm{hr}$ resulted continuous expansion of granular sludge bed, and enhanced gas-liquid separation in EGSB reactors with methane gas production of $0.30 \mathrm{~L} / \mathrm{g}-\mathrm{COD}$.

- Influent concentration of organic compounds may have a large impact on the microbial ability needed for COD reduction of the anaerobic treatment system if an average overall concentration of $3939 \mathrm{mg}-\mathrm{COD} / \mathrm{L}$ (Feed 2) can be applied in a phased 
EGSB reactor as an optimum concentration during fluctuation test,

- The high influent concentrations tested in Feed 3 can be more difficult to be reduced in a full-scale EGSB reactor. Because the applicability of the higher concentration depends on the granular sludge biomass concentrations that can be maintained in the reactor due to requiring the higher biomass rates per unit of reactor-surface.

- The time needed for start-up of the anaerobic treatment reactor may be affected by the availability of granular sludge biomass for biodegradation of organic constituents in the reactor.

\section{Acknowledgement}

This study was supported by the Research Fund, 2013 of The Catholic University of Korea and Hanseo University.

\section{References}

1. Kleerebezem R, Lettinga G. High rate anaerobic treatment of purified terephthalic acid wastewater. Water Sci. Technol. 2000; 42:259-268.

2. Garg KK, Prasad B, Srivastava VC. Comparative study of industrial and laboratory prepared purified terephthalic acid (PTA) waste water with electro-coagulation process. Sep. Purif. Technol. 2014;128:80-88.

3. Kleerebezem R, Beckers J, Pol LWH, Lettinga G. High rate treatment of terephthalic acid production wastewater in a two-stage anaerobic bioreactor. Biotechnol. Bioeng. 2005;91: 169-179.

4. Wang ZJ, Teng LH, Zhang J, Huang XL, Zhang JF. Study on optimal biodegradation of terephthalic acid by an isolated Pseudomonas sp. Afr. J. Biotechnol. 2011;10:3143-3148.

5. Lee MW, Joung JY, Lee DS, Park JM, Woo SH. Application of a moving window-adaptive neural network to the modeling of a full-scale anaerobic filter process. Ind. Eng. Chem. Res. 2005;44:3973-3782.

6. Zhang XX, Wan YQ, Cheng SP, Sun SL, Zhu CJ, Li WX, Zhang XC, Wang GL, Lu JH, Luo X, Gu JD. Purified terephthalic acid wastewater biodegradation and toxicity. J. Environ. Sci. 2005;17: 876-880.

7. Qiu YL, Sekiguchi Y, Imachi H, Kamagata Y, Tseng IC, Cheng SS, Ohashi A, Harada H. Identification and isolation of anaerobic, syntrophic phthalate isomer-degrading microbes from methanogenic sludges treating wastewater from terephthalate manufacturing. Appl. Env. Microb. 2004;70:1617-1626.

8. Pophali GR, Khan R, Dhodapkar RS, Nandy T, Devotta S. Anaerobic-aerobic treatment of PTA effluent: A techno-eco- nomic alternative to two-stage aero-bic process. J. Environ. Manage. 2007;85:1024-1033.

9. Joung JY, Lee HW, Choi HS, Lee MW, Park JM. Influences of organic loading disturbances on the performance of anaerobic filter process to treat purified terephthalic acid wastewater. Bioresour. Technol. 2009;100:2457-2461.

10. Macarie H, Guyot JP. Use of ferrous sulphate to reduce the redox potential and allow the start-up of UASB-reactors treating slowly biodegradable compounds: Application to a wastewater containing 4-methylbenzoic acid. Environ. Technol. 1995;16: 1185-1192.

11. Kleerebezem R, Hulshoff Pol LW, Lettinga G. Anaerobic degradation of phthalate isomers by methanogenic consortia. Appl. Environ. Microb. 1999;65:1152-1160.

12. Kleerebezem R, Hulshoff Pol LW, Lettinga G. The role of benzoate in anaerobic degradation of terephthalate. Appl. Environ. Microb. 1999;65:1161-1167.

13. Kleerebezem R, Mortier J, Hulshoff Pol LW, Lettinga G. Anaerobic pre-treatment of petrochemical effluents: Terephthalic acid wastewater. Water Sci. Technol. 1997;36:237-248.

14. Tsuno H, Kawamura M, Oya T. Application of biological activated carbon anaerobic reactor for treatment of hazardous chemicals. Water Sci. Technol. 2006;53:251-260.

15. Karthik M, Dafale N, Pathe P, Nandy T. Biodegradability enhancement of purified terephthalic acid wastewater by coagulation-flocculation process as pre-treatment. J. Hazard. Mater. 2008;154:721-730.

16. Fajardo C, Guyot JP, Macarie H, Monroy O. Inhibition of anaerobic digestion by terephthalic acid and its aromatic by products. Water Sci. Technol. 1997;36:83-90.

17. Young JC, Kim IS, Page IC, Wilson DR, Brown GJ, Cocci AA. Two stage anaerobic treatment of purified terephthalic acid production wastewaters. Water Sci. Technol. 2000;42:277-282.

18. Zoutberg GR, Been Pd. The Biobed® EGSB (Expanded Granular Sludge Bed) system covers shortcomings of the up-flow anaerobic sludge blanket reactor in the chemical industry. Water Sci. Technol. 1997;35:183-187.

19. Fang C, O-Thong S, Boe K, Angelidaki I. Comparison of UASB and EGSB reactors performance for treatment of raw and deoiled palm oil mill effluent (POME). J. Hazard. Mater. 2011;189: 229-234.

20. Tsuno H, Kawamura M. Development of an expanded-bed GAC reactor for anaerobic treatment of terephthalate - containing wastewater. Water Res. 2009;43:417-422.

21. Apha A. Standard Methods for the Examination of Water and Wastewater, 20th ed. Washington D.C.: American Public Health Association; 1998.

22. Baloch MI, Akunna JC, Kierans M, Collier PJ. Structural analysis of anaerobic granules in a phase separated reactor by electron microscopy. Bioresour. Technol. 2008;99:922-929. 